\title{
PENGOLAHAN MIKROALGA BERORIENTASI MASA DEPAN UNTUK INDUSTRI KOSMETIK DI ANCOL
}

\author{
Andrea Murdiono ${ }^{1)}$, Suwardana Winata ${ }^{2)}$ \\ 1)Program Studi S1 Arsitektur, Fakultas Teknik, Universitas Tarumanagara, andreadee11a@gmail.com \\ 2) Program Studi S1 Arsitektur, Fakultas Teknik, Universitas Tarumanagara, suwardanaw@dtt.untar.ac.id
}

\begin{abstract}
Abstrak
Sekarang ini bangunan dituntut untuk menunjang keberlanjutan untuk pertahanan kualitas hidup bagi lingkungan dan manusia ,baik di masa sekarang maupun di masa depan secara berkelanjutan. Arsitektur yang berusaha untuk mengurangi dampak negatif dari lingkungan dan meningkatkan efisiensi dan menunjang masa depan serta positif bagi ekosistem lingkungan. Dengan pendekatan konservasi energi maupun menciptakan lingkungan yang sehat dan desain ekologis. Mikroalga merupakan tumbuhan air yang berperan penting bagi lingkungan, yaitu sebagai produsen primer. Habitat hidupnya yang berada di area perairan dan mampu berfotosintesis dan menghasilkan oksigen. Kapasitas oksigen yang terbentuk melebihi pohon, yaitu 150 kali lipat lebih besar dari pohon. Mikroalga juga menghasilkan energi listrik dalam proses fotosintesisnya. Pada rancangan bangunan pengolahan mikroalga berorientasi masa depan yang terletak di Ancol ini, selain sebagai area pertanian mikroalga untuk diolah menjadi kosmetik, bangunan juga dapat memproduksi oksigen maupun energi listrik yang ramah bagi lingkungan. Dengan proses pertumbuhan mikroalga yang menggunakan karbon dioksida yang dapat membantu mengurangi efek pemanasan global. Kemudian dengan adanya elektron yang dihasilkan dalam proses pertumbuhan mikroalga yang dapat diolah menjadi energi listrik. Kemudian hasil limbah dari pengolahan mikroalga juga dapat digunakan kembali sebesar $70 \%$ untuk proses panen mikroalga. Kemudian sisa llimbah juga dapat langsung dibuang tanpa proses maupun pengolahan lanjut karena tingkat kekotoran sama dengan air hujan. Tidak adanya zat kimia yang digunakan dalam proses pengolahan ini juga menjadikan rancangan ramah lingkungan. Dengan demikian, rancangan bangunan pengolahan mikroalga berorientasi masa depan yang terletak di Ancol ini selain sebagai fungsinya untuk menjadi tempat perkembangan dan pengolahan mikroalga yang tujuannya sebagai materi dasar pengganti kelapa sawit. Rancangan ini juga menunjang keberlanjutan dengan menggunakan mikroalga sebagai sumber dasarnya.
\end{abstract}

Kata kunci: kosmetik; mikroalga; berkelanjutan; pengolahan

\begin{abstract}
Nowadays buildings are required to support sustainability for the defense of the quality of life for the environment and humans, both in the present and in the future in a sustainable manner. Architecture that seeks to reduce the negative impact of the environment and increase efficiency and support the future as well as positive impact to the ecosystem. With an energy conservation approach as well as creating a healthy environment and ecological design. Microalgae are aquatic plants that play an important role in the environment, namely as primary producers. Their habitat is in water areas and is able to photosynthesize and produce oxygen. The oxygen capacity that is formed exceeds the tree, which is 150 times greater than the tree. Microalgae also produce electrical energy in the process of photosynthesis that will use for productivity either for buildings and also for surrounding area. In the design of the future-oriented microalgae processing building located in Ancol, apart from being a microalgae farming area to be processed into cosmetics, the building can also produce oxygen and electrical
\end{abstract}


energy that is friendly to the environment. With a microalgae growth process that uses carbon dioxide which can help reduce the effects of global warming. Then with the electrons produced in the growth process of microalgae that can be processed into electrical energy. Then the waste from microalgae processing can also be reused by $70 \%$ for the microalgae harvesting process. Then the rest of the waste can also be directly disposed of without further processing or processing because the level of dirtiness is the same as rainwater. The absence of chemicals used in this processing also makes the design environmentally friendly. Thus, the design of the future-oriented microalgae processing building located in Ancol, apart from its function as a place for the development and processing of microalgae, is intended as a substitute for palm oil. This design also supports sustainability by using microalgae as the basic source.

Keywords: cosmetics; microalgae; sustainable; renewable energy

\section{PENDAHULUAN}

\section{Latar Belakang}

Pengolahan mikroalga merupakann pengolahan yang digunakan untuk menggantikan minyak kelapa sawit. Dengan menggunakan pengolahan mikroalga bahan dasar yang digunakan dan hasilnya ramah dengan lingkungan dan bahan yang dapat digunakan berkelanjutan. Dengan kebutuhan dasar mikroalga yaitu karbon dioksida, matahari, dan air laut, menghasilkan oksigen dalam proses fotosintesis ini dapat mengurangi polusi pada alam dan diproses tanpa menggunakan bahan kimia. Dengan menggunakan bahan mikroalga ini, bisa menunjang keberlanjutan dari bangunan maupun bersahabat dengan alam.

\section{Rumusan Permasalahan}

Dari permasalahan industri kosmetik ini menghasilkan rumusan masalah berupa cara menghasilkan mirkroalga secara efisien dan bagaimana bentuk arsitektur yang dapat mengakomodasi perkembangan mikroalga secara efisien.

\section{Tujuan}

Proyek dapat memberikan solusi terhadap masalah minyak kelapa sawit dalam industri kecantikan. Rancangan ini ditujukan juga untuk menunjang keberlanjutan dengan menggunakan mikroalga sebagai sumber dasar bahan kosmetik. Bahwa untuk menghasilkan produksi mikroalga secara maksimal yang juga menghasilkan energi listrik secara maksimal maka dibutuhkan perancangan arsitektur yang dapat mengakomodir produsi mikroalga secara efisien.

\section{KAJIAN LITERATUR} Mikroalga

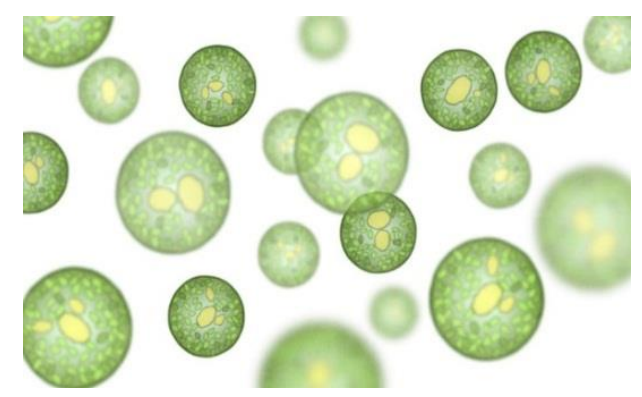

Gambar 2. Mikroalga Sumber: wikipedia.com 
Mikroalga adalah organisme tumbuhan paling primitif berukuran seluler yang umumnya dikenal dengan sebutan nama fitoplankton. Habitat hidupnya adalahwilayah perairan di seluruh dunia. Habitat hidup mikroalga adalah perairan atau tempat - tempat lembab. Organisme ini merupakan produsen primer perairan yang mampu berfotosisntesis layaknya tumbuhan tingkat tinggi lainnya. Mikroalga berperan penting dalam jaring-jaring makanan di laut dan merupakan materi organik dalam sedimen laut, sehingga diyakini sebagai salah satu komponen dasar pembentukan minyak bumi dasar laut yang dikenal sebagai fossil fuel.

Pengoptimalan kemampuan dari mikroalga dapat diperoleh melalui perancangan suatu fotobioreaktor. Fotobioreaktor merupakan bioreaktor yang menggunakan sumber cahaya. Bioreaktor adalah tempat terjadinya konversi yang melibatkan organisme tertentu menjadi suatu hasil yang dikehendaki. Fotobioreaktor terbagi menjadi dua jenis yaitu fotobioreaktor tertutup dan fotobireaktor terbuka. Kondisi pada fotobiorekator tertutup lebih mudah untuk dikontrol dan kemungkinan terkontaminasinya mikroalga lebih kecil dibandingkan dengan fotobioreaktor terbuka. Salah satu jenis fotobioreaktor tertutup adalah fotobioreaktor tubullar yang memiliki efisiensi fotosintesis tertinggi dibandingkan dengan jenis fotobioreaktor tertutup lainnya Penggunaan fotobioreaktor pada mikroalga untuk pengoptimalan konsentrasi oksigen (O2) dan mitigasi emisi gas $\mathrm{CO}$.

Fotobioreaktor merupakan bioreaktor yang menggunakan sumber cahaya (matahari, lampu halogen, LED) yang digabungkan kedalam sistem bioreaktor. Fotobioreaktor dirakit dari bahan yang tembus pandang seperti (gelas, akrilik dan plastik) dan dilengkapi dengan suplai media tertentu dan emisi gas. Salah satu faktor utama yang dipertimbangkan dalam perancangan fotobioreaktor yaitu efektifitas biaya dalam perancangan. Fotobioreaktor awalnya digunakan untuk memproduksi biomassa namun seiring berkembangnya zaman fotobioreaktor mampu dikembangkan untuk berbagai penelitian termasuk untuk memitigasi emisi gas $\mathrm{CO}$.

Sistem Photobioreactor

Budidaya massal mikroalga membutuhkan sistem kultur yang tepat. Ada teknis yang berbeda solusi untuk budidaya tersebut. Pada dasarnya mereka dapat diklasifikasikan dalam PBR terbuka (dikenal sebagai raceways), yang terbuka ke udara, dan PBR tertutup.

Manfaat dari sistem terbuka terletak pada kemudahan konstruksi. Mereka juga lebih murah untuk dibangun dan memelihara daripada sistem tertutup. Sistem terbuka dapat berupa danau, kolam, atau beberapa besar bejana terbuka yang dapat menampung air. Keterbatasan utama dari desain ini meliputi:

(a) kerentanannya terhadap penguapan;

(b) kontaminasi oleh spesies invasif, yang dapat mengambil alih kolam yang membutuhkan pengeringan dan/atau perawatan;

(c) persyaratan lahan yang luas;

(d) fluktuasi suhu yang dapat mempengaruhi pertumbuhan alga;

(e) selain itu, sekali mikroalga berkembang, juga sulit untuk mendapatkan jumlah cahaya maksimum untuk semua mikroalga karena kolamnya akan dalam dan efisien sirkulasi bermasalah.

PBR tertutup menciptakan lingkungan pertumbuhan tertutup untuk budidaya alga di mana cahaya, udara, dan nutrisi dipasok pada tingkat yang diatur untuk memastikan pertumbuhan yang optimal. Beberapa manfaat dari penutupan ini sistem tersebut adalah:

(a) kultur mikroalga dapat tumbuh bebas dari kontaminan potensial seperti mikroorganisme;

(b) mereka memberikan tingkat produksi yang lebih tinggi daripada sistem terbuka; 
(c) mereka lebih mudah untuk dimanipulasi dan kontrol, memungkinkan optimalisasi variabel penting dan memberikan tingkat pertumbuhan yang tinggi;

(d) mereka memiliki penguapan lebih sedikit daripada sistem terbuka; (e) pencahayaan interior dapat disesuaikan untuk pencahayaan yang tepat tingkat.

Masalah dengan sistem tertutup terutama melibatkan fakta bahwa mereka lebih mahal untuk disiapkan dan fasilitas membutuhkan jumlah perawatan yang lebih besar. Faktor penting dari PBR untuk memaksimalkan kondisi pertumbuhan adalah desainnya, yaitu geometri yang digunakan untuk mendapatkan distribusi cahaya yang efisien. Geometri PBR tertutup yang paling umum adalah pelat datar, annular, dan yang berbentuk tabung.
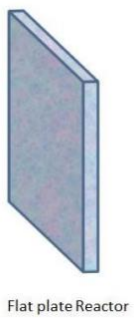

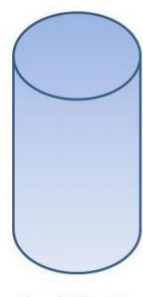

Annular Reactor

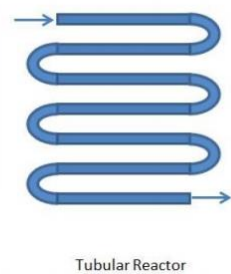

Tubular Reactor

Gambar 3. Tipe Photobioreactor

Sumber:creativecommon.org

PBR pelat datar telah menerima banyak perhatian karena luas permukaan iluminasinya yang besar. Umumnya, PBR ini terbuat dari bahan transparan untuk pemanfaatan energi cahaya matahari secara maksimal.

Akumulasi konsentrasi oksigen terlarut dalam PBR flat rate relatif rendah dibandingkan dengan PBR berbentuk tabung. Telah dilaporkan bahwa dengan PBR pelat datar, efisiensi fotosintesis yang tinggi dapat dicapai.

Reaktor anular biasanya merupakan wadah berdiameter besar yang tembus cahaya yang diisi dengan ganggang yang tersuspensi dalam medium cair, di mana gas digelembungkan dari dasar wadah. Karena tidak tepat garis aliran yang ditentukan terbentuk secara reproduktif, mungkin sulit untuk mengontrol sifat pencampuran dari sistem yang dapat menyebabkan koefisien perpindahan massa yang rendah, fotomodulasi yang buruk, dan produktivitas yang rendah.

Selain itu, untuk bekerja dengan volume yang cukup, diameter besar menyebabkan fraksi gelap yang cukup besar di tengah silinder. Bagian ini tidak berkontribusi pada produktivitas atau bahkan mungkin merugikan efek pada pertumbuhan.

PBR berbentuk tabung adalah salah satu jenis yang paling cocok untuk kultur massal di luar ruangan. Kebanyakan dari mereka adalah biasanya dibangun dengan tabung kaca atau plastik. Mereka terdiri dari lurus, melingkar atau melingkar tabung transparan diatur dalam berbagai cara untuk memaksimalkan penangkapan sinar matahari.

Dirancang dengan benar PBR tubular sepenuhnya mengisolasi kultur dari lingkungan eksternal yang berpotensi mencemari, memungkinkan kultur alga durasi panjang. Pencampuran kultur dalam PBR tubular biasanya dilakukan baik dengan pompa udara atau sistem pengangkutan udara. Desain ini sangat cocok untuk kultur massal alga di luar ruangan karena mereka memiliki luas permukaan iluminasi yang besar.

Di sisi lain, salah satu keterbatasan utama dari PBR tubular adalah transfer massa yang buruk. Perlu dicatat bahwa perpindahan massa (penumpukan oksigen) menjadi masalah ketika PBR tubular ditingkatkan. Misalnya, beberapa penelitian telah menunjukkan bahwa sangat tingkat oksigen terlarut yang tinggi mudah dicapai dalam PBR tubular. Membandingkan tiga cara rekayasa PBR tertutup, yang berbentuk tabung memfasilitasi kontrol yang lebih baik dari 
banyak parameter lingkungan budaya seperti pasokan karbon dioksida, pasokan air, optimal suhu, paparan sinar matahari yang efisien, kepadatan kultur, tingkat $\mathrm{pH}$, laju pasokan gas, atau rezim pencampuran.

Meskipun tidak semua PBR terlihat sama, pada dasarnya mereka bekerja dengan cara yang sama. Skema kerja dari sistem PBR tubular generik untuk kultur mikroalga luar ruangan. Kultur mikroalga luar ruangan hanya membutuhkan nutrisi, sinar matahari, dan karbon dioksida untuk tumbuh. Dari unit pencampuran, aliran budaya biasanya berkembang menjadi pompa yang memoderasi aliran ke dalam tabung. Dibangun ke dalam pompa adalah katup masuk CO2. Loop tubular itu sendiri, yang bertindak sebagai penerima matahari, adalah digunakan untuk mempromosikan pertumbuhan biologis dengan mengendalikan parameter lingkungan. Sensor yang berbeda biasanya tersedia di loop tubular seperti sensor oksigen untuk menentukan berapa banyak oksigen yang dimiliki dibangun di pabrik, atau $\mathrm{pH}$ atau sensor suhu. Setelah mikroalga menyelesaikan aliran melalui loop tubular, mereka melewati kembali ke unit pencampuran. Pencampuran yang efisien harus disediakan di unit ini dalam untuk menghasilkan dispersi mikroalga yang seragam dalam media kultur, sehingga menghilangkan cahaya gradien atau untuk mendistribusikan konsentrasi nutrisi. Demikian juga udara digelembungkan melalui bagian bawah unit pencampur untuk menghasilkan pencampuran keseluruhan yang baik, pasokan $\mathrm{CO} 2$ yang cukup, dan penghilangan $\mathrm{O} 2$ yang efisien.

Pada tahap ini, sensor optik menentukan tingkat panen. Ketika mikroalga siap untuk panen, mereka melewati sistem penyaringan yang terhubung. Filter ini mengumpulkan mikroalga siap untuk diproses, sedangkan mikroalga yang tersisa kembali ke unit pencampuran. Setelah memanen air dengan nutrisi dapat ditambahkan ke unit pencampuran. Sistem lain yang digabungkan ke dalam banyak PBR adalah sistem pembersihan internal yang membersihkan secara internal. Tabung tanpa menghentikan produksi. Ini adalah sistem agitasi yang mencegah mikroalga dari menempel pada dinding bejana dan mengurangi jumlah cahaya yang tersedia.

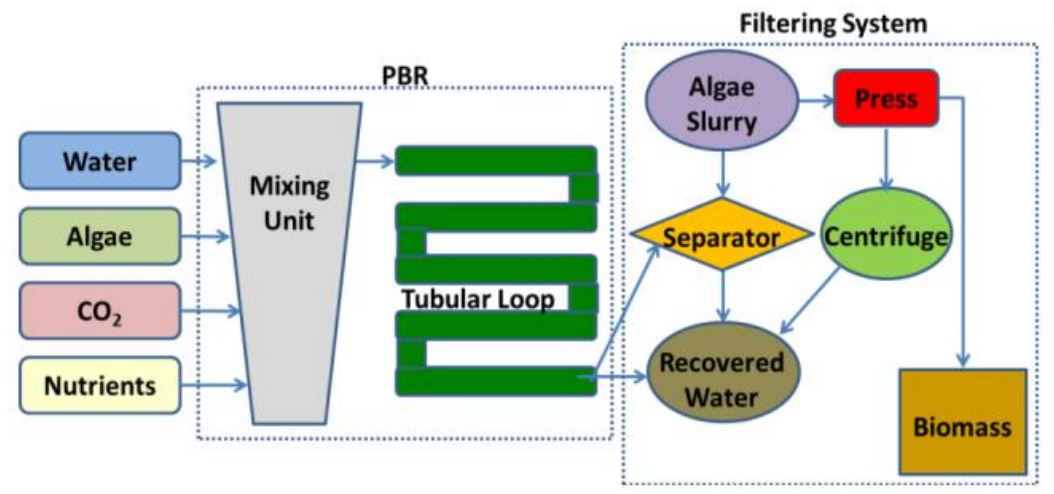

Gambar 4. Proses Pertumbuhan Mikroalga

Sumber:creativecommon.org

\section{METODE}

Pengumpulan dan pengolahan data menggunakan beberapa metode sebagai pendukung dalam proses perancangan. Beberapa metode dijelaskan sebagai berikut:

A. Data primer merupakan data yang diperoleh melalui pengamatan mengenai hal-hal penting terhadap objek perancangan serta pengamatan terhadap masalah-masalah yang ada secara langsung. Pengambilan data primer dilakukan dengan beberapa cara yaitu observasi obyek studi, observasi lingkungan sekitar tapak, dokumentasi.

B. Data sekunder merupakan data yang digunakan sebagai pendukung data- data primer yang telah didapatkan, meliputi studi pustaka. Strategi perancangan Pengolahan Mikroalga 
Berorientasi Masa Depan untuk Industri Kosmetik di Ancol terbagi atas beberapa tahapan yaitu dengan mengolah data, desain panel yang disesuaikan dengan kebutuhan fotosintesis, dan juga untuk prosesis pabrik mikroalga.

Bangunan memiliki fungsi utama untuk pertumbuhan mikroalga, kemudian dilanjutkan dengan tempat untuk prosesi dan pabrikasi untuk produksi bahan baku kosmetik. Kemudian adanya tempat publik berupa open space area pantai dan juga adanya area exhibition untuk memperlihatkan dan mengenalkan pada masyarakat mengenai proses mikroalga.

\title{
4. DISKUSI DAN HASIL
}

Bangunan ini memiliki fungsi utama untuk menghasilkan mikroalga sebagai bahan dasar kosmetik yang berorientasi masa depan, menggantikan kelapa sawit yang sekarang digunakan untuk bahan dasar kosmetik. Pengolahan mikroalga memilih lokasi tapak di Ancol karena kebutuhan dasar mikroalga berupa air laut. Selain itu bangunan ini juga membutuhkan matahari dan karbon dioksida untuk tumbuh. Bangunan yang berbentuk tower ini berguna untuk menyalurkan air lewat pipa dalam core ke atas bangunan photobioreactor.

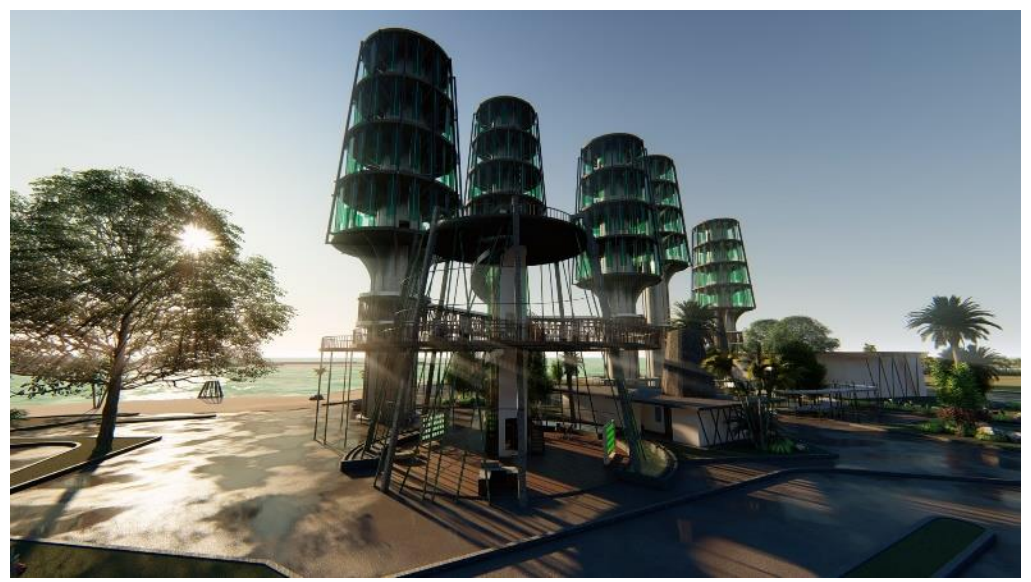

Gambar 5. Perspektif Pengolahan Mikroalga Berorientasi Masa Depan untuk Industri Kosmetik di Ancol

Sumber: Penulis, 2021

\begin{abstract}
Salah satu keuntungan dari menggunakan mikroalga sebagai bahan dasar adalah karena ia menggunakan karbon dioksida untuk tumbuh, dimana karbon dioksida sudah sangat banyak merusak lingkungan. Mikroalga dapat membantu meringankan masalah itu, kemudian hasil akhir berupa oksigen baik untuk lingkungan.
\end{abstract}

Photobioreactor adalah tempat mikroalga tumbuh, bentuk tower berfungsi untuk mengoptimalkan banyaknya cahaya matahari yang masuk. Fasad merupakan kinetic façade yang dapat berputar, in berfungsi untuk mengoptimalkan cahaya matahari yang masuk. Setiap lima menit panel photobioreactor berputar. Ini ditujukan agar cahaya matahari yang merata agar proses tumbuh mikroalga sama cepatnya.

Selama 2 minggu mikroalga tumbuh dan kemudian hasilnya akan diproses di pabrik. Lalu mikroalga yang sudah matang akan dialirkan melalui pipa shaft menuju pabrik. Melalui pabrikasi mikroalga akan diolah menjadi bubuk dan kemudian dipasarkan dan dikirimkan ke pabrik kosmetik.

Selain itu, mikroalga mempunya keuntungan yaitu selama proses tumbuhnya menghasilkan 
elektron, yang kemudian elektron ini di proses menjadi energi listrik yang digunakan untuk proses pabrikasi juga. Lalu air sisa hasil proses mikroalga dapat $70 \%$ digunakan kembali untuk proses mikroalga. Sisa limbahnya juga dapat dibuang langsung karena memiliki tingkat kotor yang setara dengan air hujan.
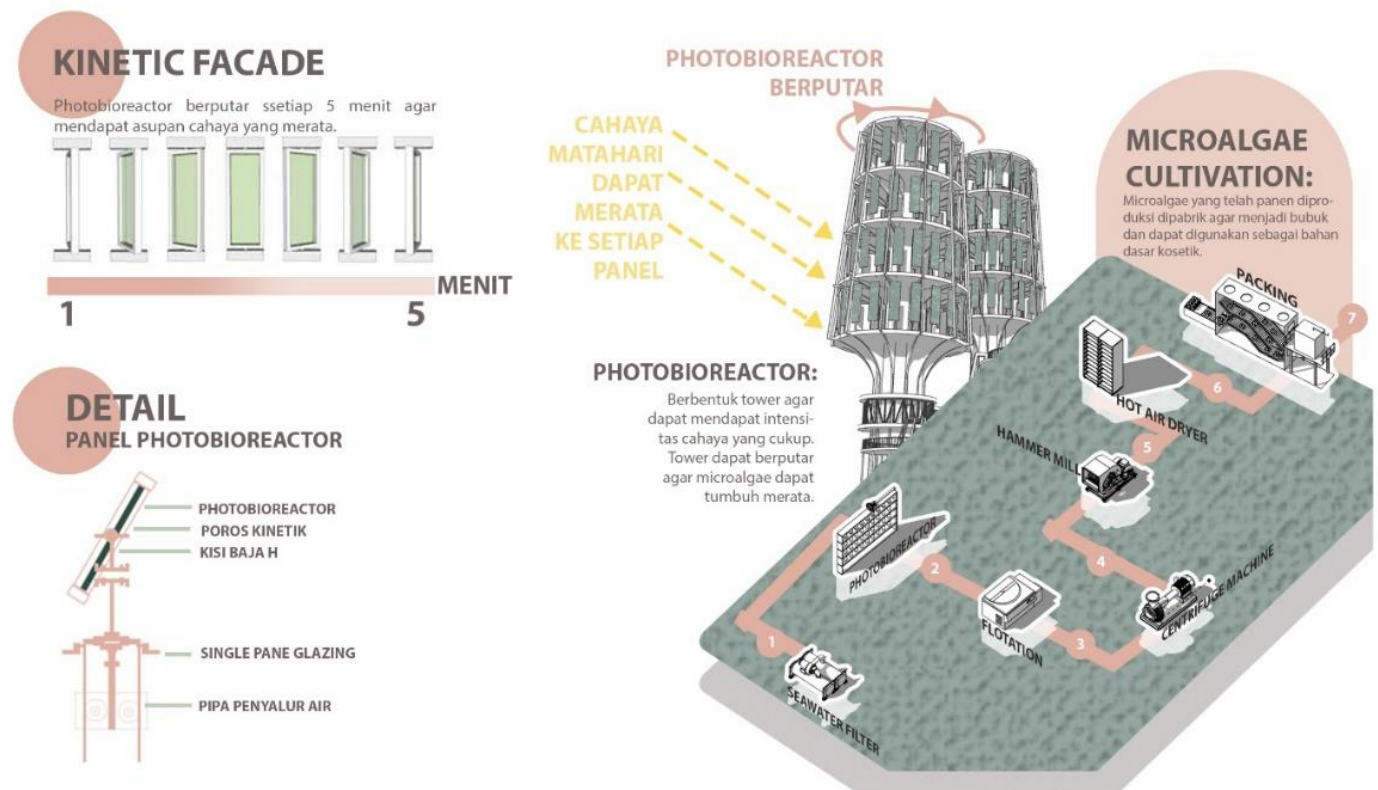

Gambar 6. Proses Tower Mikroalga

Sumber: Penulis, 2021

Photobioreactor adalah tempat mikroalga tumbuh, selama 2 minggu mikroalga akan berkembang biak dan kemudian siap dipanen. Bentuk tower berfungsi untuk mengoptimalkan banyaknya cahaya matahari yang masuk. Pada tower juga memiliki core yang berisikan pipa karbon dioksida yang dialirkan ke photobioreactor tempat mikroalga tumbuh. Ada juga pipa air laut yang diambil dari air laut yang telah diproses sebagai wadah mikroalga tumbuh. Kemudian pipa oksigen tempat semua oksigen hasil mikroalga dikumpulkan dan dilepas ke udara. Elektron hasil mikroalga juga dikumpulkan dan diprosesi di generator elektron.

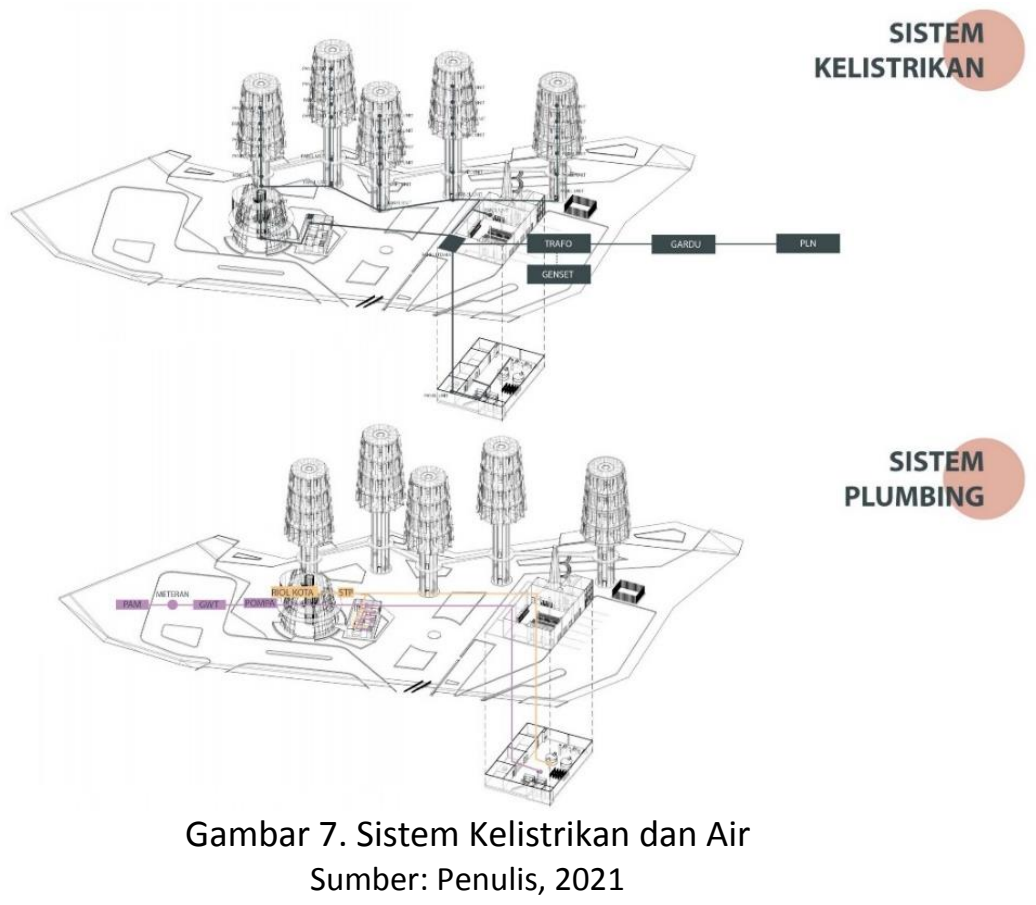




\section{KESIMPULAN DAN SARAN}

\section{Kesimpulan}

Pengolahan Mikroalga Berorientasi Masa Depan untuk Industri Kosmetik di Ancol merupakan bangunan yang berorientasi masa dengan dengan tujuan untuk memberikan material yang lebih ramah lingkungan untuk industri kosmetik. Bangunan juga berkepanjangan dengan adanya kemampuan untuk mengolah energi sendiri serta ramah lingkungan dengan tidak adanya limbah yang kotor. Semua dapat langsung dilepas kembali ke alam tanpa prosesi. Hasil dari proses pertumbuhan mikroalga yang berupa oksigen juga memberikan efek positif bagi alam. Sehingga bangunan ini menjunjung ekologi berkelanjutan untuk dunia industri kosmetik.

\section{Saran}

Bangunan ini akan lebih bermanfaat lagi bila kegunaanya dapat dikembang biakkan dan tidak hanya untuk kosmetik, dengan fungsinya yang banyak dan dapat diolah untuk berbagai hal yang lebih organik dan ramah lingkungan.

\section{REFERENSI}

Ariyanti, D., Noer A. H. (2015). Mikroalga Sebagai SumberBiomasa Terbarukan: Teknik Kultivasi Dan Pemanenan. Semarang:Universitas Diponegoro.

Atiyeh, B., Hayek, E. (2008). Numeric Expression of Aesthetics and Beauty. Aesthetic Plastic Surgery.

Becker, D., Kenrick, D., Guerin, S., Maner, J. (2005). Concentrating on Beauty: Sexual Selection and Sociospatial Memory. Personality and Social Psychology Bulletin, USA.

Renew Energ. (2014). Biodiesel frommicroalgae - Life cycle assessment and recommendations for potential improvements. London.

Widyartini, D. S. (2013). Potensi dan Kultur Mikroalga secara Bertingkatuntuk Pakan Alami. Purwokerto: Universitas Jenderal Soedirman 